\title{
Artículos
}

\section{Precios justos y tendencias de venta de productos agropecuarios mexicanos a intermediarios*}

Cómo citar este artículo: Bojórquez Carrillo, A. L., Lendechy Grajales, A. C. y Flores Novelo, A. (2020). Precios justos y tendencias de venta de productos agropecuarios mexicanos a intermediarios. Cuadernos de Desarrollo Rural, 17. https://doi.org/10.1II44/Javeriana.cdri7.pjtv

\author{
Ana Laura Bojórquez Carrillo a \\ Universidad Autónoma de Yucatán, México \\ anabc@correo.uady.mx \\ ORCID: https://orcid.org/0000-0003-0830-2508 \\ Ángel Cirilo Lendechy Grajales \\ ORCID: https://orcid.org/0000-000I-7373-365X \\ Anel Flores Novelo \\ ORCID: https://orcid.org/0000-0003-2567-8769 \\ DOI: https://doi.org/I0.III44/Javeriana.cdrı7.pjtv \\ Recibido: 08 Julio 2019 I Aceptado: 20 Septiembre 2020 I Publicación: 20 Diciembre 2020
}

\section{Resumen:}

El objetivo de este artículo es analizar el establecimiento de precios justos y las prácticas de venta a intermediarios, en el contexto de la problemática que aqueja a pequeños productores agropecuarios en ocho municipios de Yucatán, México. El enfoque de la investigación es mixto y, por este motivo, se aplicaron técnicas a nivel comparativo relacional, se construyeron modelos de regresión logística binaria y se realizaron entrevistas semiestructuradas. Los resultados obtenidos contradicen la idea de que estos productores se dirigen, principalmente, a los intermediarios para venderles sus productos, en caso de que estos tengan algún tipo de problema con respecto a la tierra, la producción, la comercialización, el transporte o la falta de precios justos.

Palabras clave: Comercio justo, productos agropecuarios, precios justos, pobreza, desarrollo local.

\footnotetext{
a Autor de correspondencia. Correo electrónico: anabc@correo.uady.mx
} 


\title{
Fair Prices and Sale Trends for Mexican Farming Products Sold to Intermediaries
}

\begin{abstract}
:
This article aims to analyze the fair pricing as well as the practices of selling to intermediaries in the context of the problems undergone by the small farming producers in eight towns in Yucatán, Mexico. The research is developed under a combined approach. To do so, relational comparative techniques were applied, binary logistic regression models were developed and semi-structured interviews were carried out. The results go against the idea that these producers want to contact mainly the intermediaries in order to have their goods sold in the case of any problem related to the land, production, marketing, transport or a lack of fair prices.
\end{abstract}

Keywords: Fair trade, farming products, fair prices, poverty, local development.

\section{Introducción}

El impacto de la liberalización comercial en el desarrollo económico de los países aún es un tema en discusión. Si bien muchos economistas argumentan que la liberalización comercial logra, en términos generales, un crecimiento económico, la evidencia empírica demuestra unos resultados mixtos, con respecto al impacto en la reducción de la pobreza (García, 20I6). En realidad, esta situación tiende a ser desfavorable en la rama agropecuario, por ejemplo, con la instrumentación de políticas neoliberales en México, tales como la apertura comercial en la década de los noventa, se propició un marco económico desfavorable que impactó, sobre todo, a los pequeños productores rurales (Goyas, 2019).

De acuerdo con Medina (2013), en los países que se encuentran en vía de desarrollo se observan dos tipos de productores agrícolas. Los primeros cuentan con el volumen de producción y niveles de operatividad suficientes para solventar los gastos de la comercialización; además, son los que acceden a los nuevos mercados con mejores precios y obtienen grandes beneficios de estos. Los segundos están representados por pequeñas unidades productivas que dependen de intermediarios para vender sus productos y se ven afectados por la competencia internacional, pues la liberación de mercados ha generado presión en los intermediarios para ofrecer a los productores, cada vez, unos menores precios y así obtener ganancias de la actividad comercial. Lo anterior tiene como resultado unas condiciones de intercambio comercial desiguales y genera desequilibrios, lo que propicia que los pequeños productores continúen viviendo en condiciones de pobreza.

En una investigación que aborda los problemas que enfrenta el pequeño productor agrícola se obtuvo como resultado que la gran mayoría de esa población percibe en la intermediación "la principal causa para no encontrar mejoras en su calidad de vida” (Díaz del Castillo, 20I3, p. 27). Asimismo, se asegura que dichos productores, al no contar con asociaciones o gremios que los respalden, se ven obligados a vender sus productos a cualquier precio, lo que hace que sus márgenes de utilidad sean bajos y que se pierdan los incentivos para permanecer en las actividades agropecuarias a largo plazo.

En este sentido, el presente estudio se enfoca en la actividad comercial de los pequeños productores del sector agropecuario, en ocho municipios de Yucatán, México, y se enfoca, especialmente, en el destino de la venta (venta al consumidor final o al intermediario), en las diferencias existentes entre los precios de venta y los precios justos (según valoración del productor) y en la problemática que enfrentan las unidades productivas. Así, el objetivo de la 
investigación es analizar el establecimiento de precios justos y las prácticas comerciales de venta a intermediarios, en el contexto de la problemática que aqueja a los pequeños productores agropecuarios en esos ocho municipios.

Este estudio se enmarca en el enfoque del comercio justo, cuyo propósito es lograr un beneficio para todos los actores involucrados en la actividad comercial, que tenga como base la justicia social, la calidad del producto y el cuidado del medio ambiente, enfocándose, en este caso, en el ámbito agropecuario de la región objeto de estudio. El comercio justo representa una alternativa al comercio tradicional. Aquel se basa en la idea de que el problema del subdesarrollo no es coyuntural, sino que se trata de un fenómeno estructural, producto de esquemas comerciales desiguales. A diferencia del comercio tradicional, que busca de cualquier manera beneficios comerciales y utilidades para el dueño del capital, el comercio justo pretende establecer mecanismos que permitan establecer relaciones de intercambio, considerando no solo los beneficios comerciales que puedan derivarse de este, sino, y sobre todo, los beneficios sociales que dichos intercambios pueden aportar (Medina y Flores, 2012).

El comercio justo es congruente con los Objetivos del Desarrollo Sostenible de la Agenda 2030 de la Organización de las Naciones Unidas (ONU), entre los que se encuentran erradicar la pobreza, la desigualdad y la exclusión social, fomentar el trabajo digno y el respeto de los derechos humanos y del medio ambiente, y cambiar los actuales patrones insostenibles de producción y consumo. Lo anterior a través de: a) un enfoque multidimensional que involucre aspectos económicos, sociales, medioambientales y políticos; b) un enfoque multistakeholder porque incluye a varios actores de las cadenas globales de valor (productores, consumidores, trabajadores, cooperativas, empresas, exportadores, entre otros), y c) un multinivel, pues atañe a los niveles locales, regionales, nacionales y globales (Coscione y Mulder, 20I7).

Según el World Fair Trade Organization (WFTO, 2019) (la Asociación Internacional de Comercio Justo, en español), son diez los principios del comercio justo los que se deben de cumplir, entre los que se encuentran:

- las prácticas de comercio justo para lograr un bienestar social, económico y medioambiental de los pequeños productores marginados, sin maximizar el beneficio de otras personas a su costa. Este principio tiene como objetivo evitar las prácticas comerciales perjudiciales de las ventas a los intermediarios o clientes que se aprovechen de los pequeños productores, quienes, ya sea por desconocimiento o por necesidad, pactan condiciones de venta desfavorables para ellos.

- un precio justo, el cual represente un pago digno para los productores y que, al mismo tiempo, sea sustentable para el mercado. Por precio justo se entiende una remuneración social aceptable -en el contexto local- que los propios productores consideren como justa, en la que también se respete la cuestión de género.

Para efectos de este trabajo, se toman como marco de referencia estos dos principios. Por prácticas de comercio justo se analizarán las tendencias de venta al intermediario y por precio justo se tomará en cuenta el valor que el productor desea en su contexto local y con el cual el trabajo, los factores de producción implementados y las ganancias que estima serían las adecuadas.

\section{Metodología}

Como ya se mencionó, el enfoque de esta investigación es mixto. 


\section{Enfoque cuantitativo}

A partir de un enfoque cuantitativo, la investigación se plantea como transversal, no experimental con alcance explicativo. En este sentido, las hipótesis que guiaron la investigación son las siguientes:

$\mathrm{H}_{\mathrm{I}}$ : se presentan diferencias significativas entre los precios de ventas y los precios justos (según valoración del productor), por destino de la venta.

$\mathrm{H}_{2}$ : a mayor porcentaje de diferencia entre el precio de venta y el precio justo (según valoración del productor), mayor es la probabilidad de que el destino de la venta sea el intermediario.

$\mathrm{H}_{3}$ : existe una mayor probabilidad de que la producción se destine al intermediario cuando la unidad productiva presenta problemas relacionados con la tierra, la producción, el transporte o la comercialización.

\section{Población objetivo}

La población objetivo del presente estudio fueron las 2364 unidades productivas y los productores de los ocho municipios de Yucatán ya mencionados, quienes conforman el padrón de beneficiarios que el proyecto de Fortalecimiento del Capital Social para Contribuir a la Seguridad y la Soberanía Alimentaria propuso atender en 2016. De este modo, la muestra estadística de unidades productivas (solares, milpas y parcelas) se tomó considerando dicho padrón y, por lo tanto, son extrapolables a las unidades productivas con características similares, de la región que integran estos mismos municipios.

La información analizada corresponde a los resultados obtenidos en la Encuesta de Producción y Comercialización (EPC), levantada durante los meses de septiembre, octubre y noviembre de 2016, elaborada en consenso por profesores que participaron en el proyecto Fortalecimiento del Capital Social para Contribuir a la Seguridad y la Soberanía Alimentaria, operado por la Universidad Autónoma de Yucatán y financiado por la Fundación Kellogg, en los municipios de Cantamayec, Chacsinkín, Maní, Mayapán, Peto, Thadziú, Tixméhuac y Tzucacab del estado de Yucatán, México.

Si bien el estudio descriptivo presenta la información de diversos productos, el estudio inferencial consideró, en particular, tres productos agrícolas y cuatro productos pecuarios seleccionados: calabaza, frijol, maíz, miel, huevo, gallina y pavo.

\section{Muestra}

El tamaño de la muestra se obtuvo para una proporción esperada del 30\%, correspondiente a los productores que destinan su producción al consumidor, con una confianza del 95\% y un error de estimación del 5\%. La muestra reside en 323 unidades productivas. Por su parte, la encuesta captó la información de una muestra efectiva de 333 unidades productivas, las cuales, de acuerdo al tipo de unidad, están integradas a nivel región por 249 solares, 53 milpas y 3 I parcelas $(74.8 \%$, I5.9\% y $9.3 \%$, respectivamente). Del total de la muestra efectiva sobre el destino de la venta de lo producido, se obtuvo que i43 vendía a los intermediarios (42.9\%) y I02 directamente a los consumidores (30.6\%), el resto no lo especificaba. 


\section{Variables}

Las variables de interés en el estudio fueron: los precios de venta y los precios justos, los problemas que enfrentan los productores y sus unidades y el destino de la venta de lo producido, con relación a 25 productos agrícolas y 7 productos agropecuarios seleccionados (véase la tabla i).

TABLA 1.

VARIABLES CONSIDERADAS EN EL ESTUDIO Y SUS CARACTERÍSTICAS

\begin{tabular}{|l|l|l|}
\hline Variable & Escala de medida & Valores que puede tomar \\
\hline $\begin{array}{l}\text { Tipo de unidad productiva } \\
\text { (UP) }\end{array}$ & Nominal & $\begin{array}{l}\text { Solar } \\
\text { Milpa } \\
\text { Parcela }\end{array}$ \\
\hline $\begin{array}{l}\text { Precio de venta (por } \\
\text { cultivo) }\end{array}$ & De razón & E1 propio precio \\
\hline Precio justo (por cultivo) & De razón & E1 propio precio \\
\hline $\begin{array}{l}\text { Porcentaje de la diferencia } \\
\text { entre el precio de venta y el } \\
\text { precio justo }\end{array}$ & De razón & E1 propio porcentaje \\
\hline $\begin{array}{l}\text { Problemas en la UP } \\
\text { producido }\end{array}$ & Nominal & $\begin{array}{l}\text { Se presenta } \\
\text { No se presenta }\end{array}$ \\
\hline $\begin{array}{l}\text { Estrato de porcentaje de la } \\
\text { diferencia entre los precios } \\
\text { de venta y precios justos }\end{array}$ & Ordinal & $\begin{array}{l}\text { Al intermediario } \\
\text { Al consumidor }\end{array}$ \\
\hline
\end{tabular}

Fuente: elaboración propia.

\section{Técnicas estadísticas}

Para el análisis de los resultados, además del estudio descriptivo correspondiente, se aplicaron, en el nivel comparativo relacional, pruebas de hipótesis de independencia, pruebas de bondad de ajuste para el porcentaje de la diferencia entre los precios de ventas y precios justos, pruebas U de Mann Whitney para dos muestras independientes; en el nivel explicativo, se tomó en cuenta la construcción de modelos de regresión logística binaria, según Hosmer y Lemeshow (2000) y Alderete (2006). 
Para la verificación de las pruebas descritas, se tomó en consideración el criterio del valor p. En general, en las tablas de resultados del presente documento, se presenta el valor $\mathrm{p}$ asociado con la verificación de las pruebas de hipótesis efectuadas.

En este documento, en primer término, se presentan los resultados descriptivos a nivel región, concernientes a la identificación de los precios de venta y los precios justos de 25 productos agrícolas y 7 productos pecuarios, por tipo de unidad productiva (solar, milpa o parcela) y destino de la venta de lo producido (intermediario o consumidor). En segundo término, se presentan los resultados de los análisis relacionales y comparativos para 7 productos seleccionados: tres productos agrícolas (calabaza, frijol y maíz) y cuatro productos pecuarios (miel, huevo, gallinas y pavos). Finalmente, se presentan los resultados de los modelos de regresión logística binaria, los cuales se construyen para analizar la relación que existe entre la presencia de problemas de la tierra, el proceso productivo, la comercialización, el transporte y la diferencia porcentual entre los precios de ventas y los precios justos, para cada uno de los 7 productos seleccionados.

\section{Enfoque cualitativo}

El análisis cualitativo se realizó desde las experiencias del proyecto Agencias de Desarrollo Humano Local (ADHLAlianzas), el cual tiene como objetivo fortalecer el capital social de las comunidades a través de la coordinación intersectorial y la participación ciudadana, para así contribuir a la seguridad y la soberanía alimentaria de las familias participantes. El contenido del análisis se sustenta en entrevistas abiertas, realizadas a 5 productores, 4 técnicos que participaron en el proyecto y el líder del proyecto, quienes han estado involucrados en el desarrollo de un mercado justo y solidario, desde el año 2013 hasta la fecha. En la entrevista semiestructurada se incluyeron 5 preguntas guía; las cuales buscaban abordar aspectos de la relación que tienen los intermediarios con un precio justo, el trato que los productores reciben de estos y la influencia de las fallas en la tierra, en el trabajo y en el capital, y cómo perciben las oportunidades y dificultades de la comercialización.

\section{Resultados}

Por una parte, de acuerdo con información del Instituto Nacional de Estadística y Geografía (Inegi), en 20ro, el I2.2\% del total de la población en Yucatán participó en el sector primario, mientras que, en el 2015, este porcentaje fue del $10.9 \%$, lo que representa un decremento de 1.3 puntos porcentuales en la ocupación en este sector, en el periodo considerado (Inegi, 20I0, 2015). El porcentaje que representa la población ocupada en el sector primario en Yucatán y que viven en la región de estudio (los 8 municipios mencionados), con respecto al total de la población ocupada, fue del $8.9 \%$ en 2010 , y $8.6 \%$ en 2015 .

Por la otra parte, con base en la información de los Censos Agropecuarios (Inegi, 2007) (la última información censal disponible al mes de junio de 2019 , a nivel regional), el $94.8 \%$ de los productores son hombres y $5.2 \%$ son mujeres, mientras que, en la región de estudio, estos porcentajes fueron del 95.7\% y el 4.3\%, respectivamente. En cualquier caso, es evidente la participación ampliamente mayor de los hombres en la realización de las tareas agrícolas en las unidades productivas.

$\mathrm{Al}$ tener en cuenta este contexto, a continuación, se presentan los resultados de los estudios descriptivo, comparativo, relacional y de nivel explicativo, obtenidos mediante el empleo del paquete estadístico IBM SPSS Statistics 22, para Windows, en el caso del enfoque cuantitativo, y, al final de esta sección, se presentan los resultados en el caso del enfoque cualitativo. 


\section{a) Estudio descriptivo}

Los principales resultados descriptivos, correspondientes a los precios de ventas y los precios justos, a nivel regional y por destino de la venta de lo producido, se presentan en las tablas 2 y 3 .

TABLA 2.

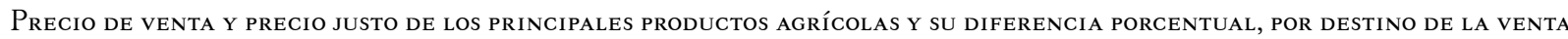

\begin{tabular}{|c|c|c|c|c|c|c|c|c|c|c|c|c|c|}
\hline \multirow{2}{*}{$\begin{array}{l}\text { Produc } \\
\text { to }\end{array}$} & \multirow{2}{*}{$\begin{array}{l}\mathbf{U} \\
\mathbf{M}\end{array}$} & \multicolumn{4}{|c|}{$\begin{array}{l}\text { Promedio de la } \\
\text { región de estudio }\end{array}$} & \multicolumn{4}{|c|}{$\begin{array}{l}\text { Venta a } \\
\text { intermediarios }\end{array}$} & \multicolumn{4}{|c|}{$\begin{array}{l}\text { Venta a } \\
\text { consumidores }\end{array}$} \\
\hline & & PV & PJ & \begin{tabular}{|l|} 
DI \\
F
\end{tabular} & $\begin{array}{l}\text { PDI } \\
\text { F }\end{array}$ & PV & PJ & $\begin{array}{l}\text { DI } \\
\text { F }\end{array}$ & $\begin{array}{l}\text { PDI } \\
\text { F }\end{array}$ & PV & PJ & $\begin{array}{l}\text { DI } \\
\text { F }\end{array}$ & $\begin{array}{l}\text { PDI } \\
\text { F }\end{array}$ \\
\hline $\begin{array}{l}\text { Espeló } \\
\mathrm{n}\end{array}$ & $\mathrm{kg}$ & $\begin{array}{l}17 . \\
20\end{array}$ & $\begin{array}{r}27 . \\
60\end{array}$ & $\begin{array}{l}10 . \\
4\end{array}$ & 60.5 & $\begin{array}{l}15 . \\
40\end{array}$ & $\begin{array}{r}27 . \\
30\end{array}$ & $\begin{array}{l}11 . \\
9\end{array}$ & 77.0 & $\begin{array}{r}18 . \\
50\end{array}$ & $\begin{array}{r}28 . \\
40\end{array}$ & 9.8 & 53.1 \\
\hline Ibes & $\mathrm{kg}$ & $\begin{array}{l}32 . \\
40\end{array}$ & $\begin{array}{r}40 . \\
60\end{array}$ & 8.2 & 25.3 & $\begin{array}{l}27 . \\
90\end{array}$ & $\begin{array}{r}41 . \\
20\end{array}$ & $\begin{array}{l}13 . \\
3\end{array}$ & 47.6 & $\begin{array}{r}35 . \\
70\end{array}$ & $\begin{array}{r}40 . \\
10\end{array}$ & 4.4 & 12.4 \\
\hline Pepino & $\mathrm{kg}$ & $\begin{array}{l}12 . \\
10\end{array}$ & $\begin{array}{r}15 . \\
10\end{array}$ & 3.0 & 24.8 & $\begin{array}{l}14 . \\
20\end{array}$ & $\begin{array}{l}18 . \\
00\end{array}$ & 3.8 & 26.8 & $\begin{array}{r}7.4 \\
0\end{array}$ & $\begin{array}{r}9.4 \\
0\end{array}$ & 2.0 & 27.2 \\
\hline $\begin{array}{l}\text { Lechug } \\
\text { a }\end{array}$ & $\mathrm{kg}$ & $\begin{array}{l}32 . \\
90\end{array}$ & $\begin{array}{r}43 . \\
10\end{array}$ & $\begin{array}{l}10 . \\
2\end{array}$ & 31.0 & $\begin{array}{l}36 . \\
00\end{array}$ & $\begin{array}{r}47 . \\
40\end{array}$ & $\begin{array}{l}11 . \\
4\end{array}$ & 31.7 & $\begin{array}{r}25 . \\
00\end{array}$ & $\begin{array}{r}32 . \\
50\end{array}$ & 7.5 & 30.0 \\
\hline Lima & $\mathrm{kg}$ & $\begin{array}{r}6.8 \\
0\end{array}$ & $\begin{array}{r}11 . \\
20\end{array}$ & 4.4 & 64.7 & $\begin{array}{r}6.4 \\
0\end{array}$ & $\begin{array}{r}12 . \\
50\end{array}$ & 6.0 & 93.6 & $\begin{array}{r}7.6 \\
0\end{array}$ & $\begin{array}{r}9.3 \\
0\end{array}$ & 1.7 & 22.6 \\
\hline Limón & $\mathrm{kg}$ & $\begin{array}{l}10 . \\
70\end{array}$ & $\begin{array}{r}14 . \\
10\end{array}$ & 3.4 & 31.8 & $\begin{array}{r}0.0 \\
0\end{array}$ & $\begin{array}{r}0.0 \\
0\end{array}$ & - & - & $\begin{array}{r}6.3 \\
0\end{array}$ & $\begin{array}{r}15 . \\
60\end{array}$ & 9.3 & $\begin{array}{l}148 . \\
3\end{array}$ \\
\hline Mamey & $\mathrm{kg}$ & $\begin{array}{r}5.0 \\
0\end{array}$ & $\begin{array}{r}8.1 \\
0\end{array}$ & 3.1 & 62.0 & $\begin{array}{r}4.7 \\
0\end{array}$ & $\begin{array}{r}7.5 \\
0\end{array}$ & 2.9 & 61.3 & $\begin{array}{r}6.0 \\
0\end{array}$ & $\begin{array}{r}9.7 \\
0\end{array}$ & 3.7 & 61.1 \\
\hline Mango & $\mathrm{kg}$ & $\begin{array}{r}7.8 \\
0\end{array}$ & $\begin{array}{r}10 . \\
30\end{array}$ & 2.5 & 32.1 & $\begin{array}{r}8.6 \\
0\end{array}$ & $\begin{array}{r}9.4 \\
0\end{array}$ & 0.9 & 10.2 & $\begin{array}{r}7.3 \\
0\end{array}$ & $\begin{array}{r}10 . \\
80\end{array}$ & 3.5 & 48.2 \\
\hline $\begin{array}{l}\text { Naranj } \\
\text { a agria }\end{array}$ & $\mathrm{kg}$ & $\begin{array}{r}7.3 \\
0\end{array}$ & $\begin{array}{r}9.4 \\
0\end{array}$ & 2.1 & 28.8 & $\begin{array}{r}9.2 \\
0\end{array}$ & $\begin{array}{r}12 . \\
60\end{array}$ & 3.4 & 37.3 & $\begin{array}{r}4.1 \\
0\end{array}$ & $\begin{array}{r}4.1 \\
0\end{array}$ & 0.0 & 0.2 \\
\hline Papaya & $\mathrm{kg}$ & $\begin{array}{r}7.5 \\
0\end{array}$ & $\begin{array}{r}12 . \\
50\end{array}$ & 5.0 & 66.7 & $\begin{array}{r}8.5 \\
0\end{array}$ & $\begin{array}{l}14 . \\
00\end{array}$ & 5.5 & 64.7 & $\begin{array}{r}6.2 \\
0\end{array}$ & $\begin{array}{l}11 . \\
00\end{array}$ & 4.8 & 78.4 \\
\hline $\begin{array}{l}\text { Saramu } \\
\text { yo }\end{array}$ & $\mathrm{kg}$ & $\begin{array}{l}12 . \\
00\end{array}$ & $\begin{array}{r}20 . \\
00\end{array}$ & 8.0 & 66.7 & $\begin{array}{r}0.0 \\
0\end{array}$ & $\begin{array}{r}0.0 \\
0\end{array}$ & - & - & $\begin{array}{l}12 . \\
00\end{array}$ & $\begin{array}{r}20 . \\
00\end{array}$ & 8.0 & 66.7 \\
\hline
\end{tabular}

UM: unidad de medida; PV: precio de venta (pesos); PJ: precio justo (pesos); DIF: diferencia entre el precio justo y el precio de venta (pesos); PDIF: porcentaje de la diferencia entre el precio justo y el precio de venta respecto al precio de venta (\%). Fuente: elaboración propia. 
TABLA 3.

Precio de Venta y PRECIO JUSTO DE LOS PRINCIPAleS PRODUCTOS PECUARIOS Y SU DifERENCIA PORCENTUAL, POR DESTINO DE LA VENTA

\begin{tabular}{|c|c|c|c|c|c|c|c|c|c|c|c|c|c|}
\hline \multirow{2}{*}{$\begin{array}{l}\text { Prod } \\
\text { ucto }\end{array}$} & \multirow{2}{*}{ UM } & \multicolumn{4}{|c|}{$\begin{array}{l}\text { Promedio de la } \\
\text { región }\end{array}$} & \multicolumn{4}{|c|}{$\begin{array}{l}\text { Venta a } \\
\text { intermediarios }\end{array}$} & \multicolumn{4}{|c|}{$\begin{array}{l}\text { Venta a } \\
\text { consumidores }\end{array}$} \\
\hline & & & PJ & $\begin{array}{l}\text { DI } \\
\text { F }\end{array}$ & PD & PV & PJ & \begin{tabular}{|l|} 
DI \\
F
\end{tabular} & $\begin{array}{l}\text { PD } \\
\text { IF }\end{array}$ & $V$ & PJ & $\begin{array}{l}\text { DI } \\
\text { F }\end{array}$ & $\begin{array}{l}\text { PD } \\
\text { IF }\end{array}$ \\
\hline Miel & $\mathrm{kg}$ & 70 & $\begin{array}{r}9.8 \\
0\end{array}$ & 9.1 & 6 & $\begin{array}{r}1.6 \\
0\end{array}$ & $\begin{array}{r}9.4 \\
0\end{array}$ & 7.8 & $\begin{array}{l}24 . \\
6\end{array}$ & $\begin{array}{r}27 . \\
30\end{array}$ & $\begin{array}{r}1.0 \\
0\end{array}$ & $\begin{array}{l}13 . \\
7\end{array}$ & $\begin{array}{l}50 . \\
0\end{array}$ \\
\hline $\begin{array}{l}\text { Abej } \\
\text { as }\end{array}$ & $\begin{array}{l}\text { Colm } \\
\text { enas }\end{array}$ & $\begin{array}{r}867 \\
.60\end{array}$ & $\begin{array}{l}112 \\
9.30\end{array}$ & $\begin{array}{l}26 \\
1.7\end{array}$ & $\begin{array}{l}30 . \\
2\end{array}$ & $\begin{array}{r}931 . \\
90\end{array}$ & $\begin{array}{r}127 \\
2.70\end{array}$ & $\begin{array}{l}34 \\
0.8\end{array}$ & $\begin{array}{l}36 . \\
6\end{array}$ & $\begin{array}{r}866 \\
.70\end{array}$ & $\begin{array}{r}966 . \\
70\end{array}$ & $\begin{array}{l}10 \\
0.0\end{array}$ & $\begin{array}{l}11 . \\
5\end{array}$ \\
\hline Huev & $s$ & $\begin{array}{r}2.0 \\
0\end{array}$ & 2.50 & 0.5 & 0 & 2.00 & 2.50 & 0.5 & $\begin{array}{l}25 . \\
6\end{array}$ & $\begin{array}{r}2.0 \\
0\end{array}$ & 2.50 & 0.5 & $\begin{array}{l}25 . \\
3\end{array}$ \\
\hline $\begin{array}{l}\text { Galli } \\
\text { nas }\end{array}$ & zas & $\begin{array}{r}98 . \\
80\end{array}$ & $\begin{array}{r}126 . \\
70\end{array}$ & $\begin{array}{l}27 . \\
9\end{array}$ & $\begin{array}{l}28 . \\
2\end{array}$ & $\begin{array}{l}.2 \\
0\end{array}$ & $\begin{array}{r}96.2 \\
0\end{array}$ & $\begin{array}{l}11 . \\
1\end{array}$ & $\begin{array}{l}13 . \\
0\end{array}$ & $\begin{array}{r}116 \\
.10\end{array}$ & $\begin{array}{r}160 . \\
30\end{array}$ & 2 & $\begin{array}{l}38 . \\
1\end{array}$ \\
\hline Pavo & $\begin{array}{l}\text { Cabe } \\
\text { zas }\end{array}$ & $\begin{array}{r}439 \\
.70\end{array}$ & $\begin{array}{r}512 . \\
60\end{array}$ & $\begin{array}{l}72 . \\
9\end{array}$ & $\begin{array}{l}16 . \\
6\end{array}$ & $\begin{array}{r}468 . \\
60\end{array}$ & $\begin{array}{r}557 . \\
10\end{array}$ & $\begin{array}{l}88 . \\
6\end{array}$ & $\begin{array}{l}18 . \\
9\end{array}$ & $\begin{array}{r}417 \\
.20\end{array}$ & $\begin{array}{r}477 . \\
90\end{array}$ & $\begin{array}{l}60 . \\
7\end{array}$ & $\begin{array}{l}14 . \\
5\end{array}$ \\
\hline $\begin{array}{l}\text { Cerd } \\
\text { os }\end{array}$ & $\begin{array}{l}\text { Cabe } \\
\text { zas }\end{array}$ & $\begin{array}{r}985 \\
.90\end{array}$ & $\begin{array}{r}146 \\
5.00\end{array}$ & $\begin{array}{l}47 \\
9.1\end{array}$ & $\begin{array}{l}48 . \\
6\end{array}$ & $\begin{array}{r}108 \\
7.60\end{array}$ & $\begin{array}{r}188 \\
4.50\end{array}$ & $\begin{array}{l}79 \\
6.9\end{array}$ & $\begin{array}{l}73 . \\
3\end{array}$ & $\begin{array}{r}977 \\
.90\end{array}$ & $\begin{array}{r}128 \\
9.40\end{array}$ & $\begin{array}{l}31 \\
1.4\end{array}$ & $\begin{array}{l}31 . \\
8\end{array}$ \\
\hline $\begin{array}{l}\text { Carn } \\
\text { eros }\end{array}$ & $\begin{array}{l}\text { Cabe } \\
\text { zas }\end{array}$ & $\begin{array}{r}482 \\
.10\end{array}$ & $\begin{array}{r}605 . \\
40\end{array}$ & $\begin{array}{l}12 \\
3.3\end{array}$ & $\begin{array}{l}25 . \\
6\end{array}$ & $\begin{array}{r}431 . \\
20\end{array}$ & $\begin{array}{r}548 . \\
90\end{array}$ & $\begin{array}{l}11 \\
7.7\end{array}$ & $\begin{array}{l}27 . \\
3\end{array}$ & $\begin{array}{r}566 \\
.80\end{array}$ & $\begin{array}{r}690 . \\
20\end{array}$ & $\begin{array}{l}12 \\
3.3\end{array}$ & $\begin{array}{l}21 . \\
8\end{array}$ \\
\hline
\end{tabular}

UM: unidad de medida; PV: precio de venta (pesos); PJ: precio justo (pesos); DIF: diferencia entre el precio justo y el precio de venta (pesos); PDIF: porcentaje de la diferencia entre el precio justo y el precio de venta respecto al precio de venta (\%). Fuente: elaboración propia.

En el caso de los productos agrícolas, el porcentaje de la diferencia entre los precios de ventas y los precios justos para intermediarios va del 10.2\%, en el caso del mango, hasta 93.6\%, en el caso de la lima, con un promedio general, considerando todos los productos agrícolas estudiados, del 53.I\%. Mientras tanto, para los consumidores el porcentaje va del $0.2 \%$, en el caso de la naranja agria, hasta el I $48.3 \%$, en el caso del limón, con un promedio general, considerando todos los productos agrícolas estudiados, del 47.6\%. Según lo anterior y en un nivel descriptivo, podría decirse que se presenta un porcentaje de la diferencia entre los precios de ventas y los precios justos, mayor para los intermediarios que para los consumidores.

En el caso de los productos pecuarios, el porcentaje de la diferencia entre los precios de ventas y los precios justos para intermediarios va desde el $13 \%$, en el caso de las gallinas, hasta un $73.3 \%$, en el caso de los cerdos, con un promedio general del 31\%. Para consumidores, va del $11.5 \%$, en el caso de las abejas, hasta el 50\%, en el caso de la miel, con un promedio general del $27.6 \%$. Se concluye, entonces, que se presenta un porcentaje de la diferencia entre los precios de venta y los precios justos, mayor para los intermediarios que para los consumidores. 


\section{b) Estudio inferencial}

En la realización de los análisis estadísticos inferenciales comparativo, relacional y explicativo, se seleccionaron 3 productos agrícolas y 4 agropecuarios que, a nivel de unidades de producción, presentaron la mayor regularidad en la información captada, es decir, que esta estuviese completa, con una proporción de la diferencia entre precios de ventas y precios justos no mayor al $40 \%$ y que contribuyese de manera importante a la producción agropecuaria de la región. Al atender a estas consideraciones, los productos agropecuarios para llevar a cabo estos análisis fueron, en el caso de los productos agrícolas, calabaza, frijol y maíz, y en el caso de los productos pecuarios, miel, huevo, gallinas y pavos. En la tabla 4 se presenta el número de unidades productivas que contaron con la información completa, para poder llevar a cabo los análisis del estudio inferencial.

TABLA 4.

UNIDADES PRODUCTIVAS QUE OBTIENEN LOS PRODUCTOS SELECCIONADOS

\begin{tabular}{|l|l|l|}
\hline Producto & $\begin{array}{l}\text { Unidades productivas } \\
\text { consideradas en a) }\end{array}$ & $\begin{array}{l}\text { Unidades productivas } \\
\text { consideradas en b) }\end{array}$ \\
\hline & & \\
\hline Productos agricolas & & \\
\hline Calabaza & 102 & 67 \\
\hline Frijol & 53 & 43 \\
\hline Maiz & 76 & 62 \\
\hline Productos pecuarios & & \\
\hline Miel & 63 & 52 \\
\hline Huevo & 45 & 41 \\
\hline Gallinas & 63 & 55 \\
\hline Pavos & 31 & 30 \\
\hline
\end{tabular}

a) consideradas en los análisis comparativos y relacionales, y b) consideradas en los modelos de regresión logística binaria. Fuente: elaboración propia.

\section{Estudio comparativo relacional}

Los resultados obtenidos de los análisis relacional y comparativo, de los precios de los siete productos agropecuarios seleccionados, se presentan a continuación. 


\section{Diferencias entre el precio de venta y el precio justo por destino de la venta}

Para verificar la primera hipótesis de investigación y dada la naturaleza cuantitativa del porcentaje de la diferencia entre el precio de venta y el precio justo por producto, se empleó la prueba de bondad de ajuste de Kolmogorov Smirnov, para así verificar el supuesto de normalidad, el cual, sin embargo, no se confirmó. Por esta razón, se llevaron a cabo pruebas U de Mann Whitney para dos muestras independientes, a fin de analizar la posible existencia de diferencias significativas en los promedios de dicha variable por destino de la venta (intermediario o consumidor). Los resultados de esta última prueba arrojan que, en el caso de los productos agrícolas y pecuarios seleccionados, no se presentan diferencias estadísticamente significativas entre los valores medios de los porcentajes de las diferencias, entre los precios de ventas y los precios justos por destino de la venta. Los resultados obtenidos permiten concluir que, para los productos agrícolas y pecuarios seleccionados, los porcentajes de las diferencias entre el precio de venta y el precio justo por destino de venta son semejantes, excepto en el caso de la miel.

En el caso específico de la miel, se presentan diferencias estadísticamente significativas (valor p de 0.013 ), entre los valores medios de los porcentajes de las diferencias entre el precio de venta y el precio justo por destino de la venta, pues fue mayor el promedio en el caso del destino correspondiente al consumidor (9.5\%) que en el caso del intermediario $(6.7 \%)$.

\section{c) Modelos de regresión logística binaria por producto}

A nivel explicativo y con el objeto de verificar las siguientes hipótesis de investigación $\left(\mathrm{H}_{2}\right.$ y $\left.\mathrm{H}_{3}\right)$, referente al análisis de la relación entre el destino de la venta (como variable dependiente) y el porcentaje de la diferencia entre los precios de ventas y los precios justos, además de los tipos de problemas que enfrentan los productores (como variables independientes), se construyó un modelo de regresión logística binaria por producto.

Con relación a la variable destino de la venta de lo producido, el valor o se asignó al destino de venta Intermediario y, el valor I, al destino de venta Consumidor.

En cuanto a las variables independientes, respecto al tipo de problemas que enfrentan los productores, se consideraron cuatro tipos principales:

a) De la tierra, en el que se incluyen problemas del suelo, riego o plagas.

b) De la producción, que incluye las mermas, mermas poscosecha y los relacionados con la disponibilidad de los insumos.

c) Comercialización, que se relaciona con los canales de distribución y comercialización.

d) Trasporte, que atañe a la logística necesaria para transportar los productos para su venta.

Para cada uno de estos cuatro tipos de problemas, se asignó una variable con dos valores posibles: $\odot$ No presenta el problema, y i Si presenta el problema.

Finalmente, se estratificó previamente la variable porcentaje de la diferencia entre los precios de ventas y precios justos en dos grupos, con dos valores asignados: ○ Hasta 25\% y i Más de 25 y basta 50\%. Por esta razón, no se 
consideraron los registros para los cuales esta diferencia porcentual fuese mayor al 50\%, esto con el fin de no considerar resultados atípicos.

El resumen de los resultados obtenidos de los modelos construidos, con relación a los productos agrícolas y pecuarios seleccionados, así como de las principales pruebas de bondad de ajuste de dichos modelos (que, en general, resultaron ser satisfactorias), se presentan a continuación.

\section{a) Productos agrícolas}

Se elaboraron tres modelos de regresión logística, cuyos resultados se resumen en la tabla 5.

TABLA 5 .

Productos Agrícolas: COEFICIENTES DE REgRESIÓN Y VALORES P DE LOS MODELOS DE REGRESIÓN LOGÍSTICA BINARIA PARA LOS CULTIVOS SELECCIONADOS Y RESULTADOS DE LAS PRUEBAS DE AJUSTE

\begin{tabular}{|l|l|l|l|}
\hline Variable / Prueba & Calabaza & Frijol & Maíz \\
\hline $\begin{array}{l}\text { Problemas de la } \\
\text { tierra }\end{array}$ & $-1.723\left(0.013^{* *}\right) \mathrm{ES}$ & $-1.113(0.242) \mathrm{NS}$ & $-0.090(0.880) \mathrm{NS}$ \\
\hline $\begin{array}{l}\text { Problemas de } \\
\text { producción }\end{array}$ & $0.050(0.951) \mathrm{NS}$ & $1.501(0.113) \mathrm{NS}$ & $0.332(0.577) \mathrm{NS}$ \\
\hline $\begin{array}{l}\text { Problemas de } \\
\text { comercialización }\end{array}$ & $-0.601(0.380) \mathrm{NS}$ & $-0.863(0.367) \mathrm{NS}$ & $-0.220(0.802) \mathrm{NS}$ \\
\hline $\begin{array}{l}\text { Problemas de } \\
\text { transporte }\end{array}$ & $1.662(0.111) \mathrm{NS}$ & $\begin{array}{l}2.795(0.003 * * *) \\
\text { ES }\end{array}$ & $0.128(0.859) \mathrm{NS}$ \\
\hline $\begin{array}{l}\text { Estrato del } \\
\text { porcentaje de la } \\
\text { diferencia entre el } \\
\text { precio de venta y el } \\
\text { precio justo }\end{array}$ & $-0.844(0.177) \mathrm{NS}$ & $-1.517(0.116) \mathrm{NS}$ & $-0.328(0.625) \mathrm{NS}$ \\
\hline Constante & $1.485\left(0.022^{* *}\right) \mathrm{ES}$ & $-0.175(0.865) \mathrm{NS}$ & $0.387(0.507) \mathrm{NS}$ \\
\hline $\begin{array}{l}\text { Capacidad } \\
\text { predictiva global }\end{array}$ & $71.9 \%$ & $83.3 \%$ & 0.012 \\
\hline $\begin{array}{l}\text { R de Nagelkerke } \\
\text { Lemeshow }\end{array}$ & 0.266 & $0.163 \mathrm{NS}$ & $0.244 \mathrm{NS}$ \\
\hline Prueba de Hosmer & $0.428 \mathrm{NS}$ & 0.482 & \\
\hline
\end{tabular}

$\left(^{* *}\right) 0.01<$ valor $\left.\mathrm{p} \leq 0.05 ;{ }^{(* * *}\right)$ valor $\mathrm{p} \leq 0.0 \mathrm{I}$; NS: No significativo; ES: Significativo. Fuente: elaboración propia. 
En la descripción de los resultados obtenidos de los modelos construidos, Prob ( $Y=\mathrm{I})$ representa la probabilidad de que el destino de venta sea el consumidor, $x_{\mathrm{I}}$ a $x_{4}$ corresponden a la presencia de problemas de la tierra $\left(x_{\mathrm{I}}\right)$, producción $\left(x_{1}\right)$, comercialización $\left(x_{1}\right)$ y transporte y $x_{5}$ corresponde al estrato del porcentaje de la diferencia entre el precio de venta y el precio justo. El modelo general queda expresado, entonces, de la siguiente manera:

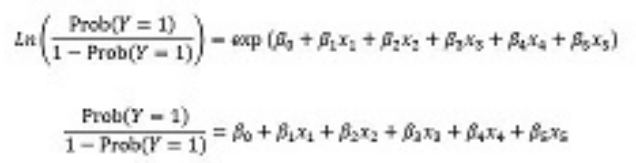

O también:

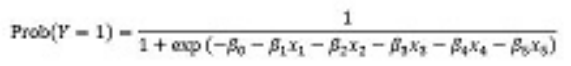

Esta última expresión es la que se empleará en la presentación de los modelos obtenidos.

\section{Calabaza}

En el caso de la calabaza, el modelo de regresión logística presenta una capacidad predictiva del 7r.9\% y resultan ser estadísticamente significativos los coeficientes correspondientes a los problemas de la tierra y la constante del modelo. De acuerdo con el signo negativo del coeficiente de regresión $\left(\beta_{1}=-1.723\right)$, el tener problemas con la tierra aumenta la probabilidad de que el productor destine las ventas al intermediario, ya que el valor del $\exp \left(\beta_{\mathrm{I}}\right)=0.178$ indica que la probabilidad de que destine la venta al consumidor disminuye en un factor de 0.822 , es decir, en un 82.2\%. El modelo de regresión logística obtenido que incluye todas las variables objeto de estudio se presenta a continuación:

$$
\operatorname{Prob}(Y=1)=\frac{1}{1+\exp \left(-1.485+1.723 x_{1}-0.05 x_{2}+0.601 x_{3}-1.662 x_{4}+0.844 x_{5}\right)}
$$

\section{Frijol}

En el caso del frijol, el modelo de regresión logística tiene una capacidad predictiva del $83.3 \%$ y resulta ser estadísticamente significativo el coeficiente correspondiente a los problemas de transporte. De acuerdo con el signo positivo del coeficiente de regresión $\left(\beta_{4}=2.795\right)$, el tener problemas con el transporte aumenta la probabilidad de que el productor destine las ventas al consumidor, atendiendo al valor del $\exp \left(\beta_{4}\right)=16.4$. El modelo de regresión logística obtenido que incluye todas las variables objeto de estudio es:

$$
\operatorname{Pros}(Y=1)=\frac{1}{1+\exp \left(0.175+1.113 x_{2}-1.501 x_{2}+0.863 x_{3}-2.795 x_{4}+1.517 x_{5}\right)}
$$

\section{Maíz}

En el caso del maíz, ninguno de los coeficientes de regresión del modelo resultó ser estadísticamente significativo. Lo anterior permite afirmar que, con relación a este cultivo, el destino de la venta de la producción no depende de la problemática de la unidad productiva ni del porcentaje de la diferencia entre el precio de venta y el precio justo. El modelo de regresión logística considerado que incluye todas las variables objeto de estudio es el siguiente:

$$
\operatorname{Prob}(Y=1)=\frac{1}{1+\exp \left(-0.387+0.000 x_{1}-0.332 x_{2}+0.22 x_{3}-0.128 x_{4}+0.328 r_{8}\right)}
$$




\section{b) Productos pecuarios}

Se elaboraron cuatro modelos de regresión logística, cuyos resultados se muestran en la tabla 6.

TABLA 6.

Productos Pecuarios: Resultados de los modelos De Regresión LOGÍSTICA BINARIA PARA CULTIVOS SELECCIONADOS Y PRUEBAS DE AJUSTE

\begin{tabular}{|c|c|c|c|c|}
\hline $\begin{array}{l}\text { Variable / } \\
\text { Prueba }\end{array}$ & Miel & Huevo & Gallina & Pavo \\
\hline $\begin{array}{l}\text { Problemas de la } \\
\text { tierra }\end{array}$ & $\begin{array}{l}-1.193(0.194) \\
\text { NS }\end{array}$ & $\begin{array}{l}0.651(0.397) \\
\text { NS }\end{array}$ & $\begin{array}{l}0.023(0.971) \\
\text { NS }\end{array}$ & $\begin{array}{l}-0.660(0.505) \\
\text { NS }\end{array}$ \\
\hline $\begin{array}{l}\text { Problemas de } \\
\text { producción }\end{array}$ & $\begin{array}{l}0.921(0.230) \\
\text { NS }\end{array}$ & $\begin{array}{l}-0.159(0.815) \\
\text { NS }\end{array}$ & $\begin{array}{l}1.119\left(0.073^{*}\right) \\
\text { ES }\end{array}$ & $\begin{array}{l}0.547(0.537) \\
\text { NS }\end{array}$ \\
\hline $\begin{array}{l}\text { Problemas de } \\
\text { comercialización }\end{array}$ & $\begin{array}{l}-0.121(0.878) \\
\text { NS }\end{array}$ & $\begin{array}{l}-0.053(0.948) \\
\text { NS }\end{array}$ & $\begin{array}{l}-0.261(0.687) \\
\text { NS }\end{array}$ & $\begin{array}{l}0.665(0.476) \\
\text { NS }\end{array}$ \\
\hline $\begin{array}{l}\text { Problemas de } \\
\text { transporte }\end{array}$ & $\begin{array}{l}0.940(0.296) \\
\text { NS }\end{array}$ & $\begin{array}{l}-0.311(0.720) \\
\text { NS }\end{array}$ & $\begin{array}{l}0.433(0.510) \\
\text { NS }\end{array}$ & $\begin{array}{l}1.269(0.171) \\
\text { NS }\end{array}$ \\
\hline $\begin{array}{l}\text { Estrato del } \\
\text { porcentaje de la } \\
\text { diferencia entre } \\
\text { el precio de } \\
\text { venta y el precio } \\
\text { justo }\end{array}$ & $\begin{array}{l}1.432(0.063 *) \\
\text { ES }\end{array}$ & $\begin{array}{l}-0.587(0.385) \\
\text { NS }\end{array}$ & $\begin{array}{l}0.967(0.249) \\
\text { NS }\end{array}$ & $\begin{array}{l}2.421\left(0.073^{*}\right) \\
\text { ES }\end{array}$ \\
\hline Constante & $\begin{array}{l}-1.552(0.116) \\
\text { NS }\end{array}$ & $\begin{array}{l}-0.014(0.986) \\
\text { NS }\end{array}$ & $\begin{array}{l}-0.774(0.205) \\
\text { NS }\end{array}$ & $\begin{array}{l}-0.874(0.404) \\
\text { NS }\end{array}$ \\
\hline $\begin{array}{l}\mathrm{R}^{2} \mathrm{de} \\
\text { Nagelkerke }\end{array}$ & 0.193 & 0.057 & 0.116 & 0.301 \\
\hline $\begin{array}{l}\text { Prueba de } \\
\text { Hosmer } \\
\text { Lemeshow }\end{array}$ & $0.144 \mathrm{NS}$ & $0.942 \mathrm{NS}$ & $0.556 \mathrm{NS}$ & $0.195 \mathrm{NS}$ \\
\hline $\begin{array}{l}\text { Capacidad } \\
\text { predictiva global }\end{array}$ & $78.4 \%$ & $65.0 \%$ & $65.4 \%$ & $70.0 \%$ \\
\hline
\end{tabular}

$\left.{ }^{*}\right) 0.05<$ valor P $\leq$ 0.1; NS: No significativo; ES: Significativo. Fuente: elaboración propia.

Miel

En el caso de la miel, el modelo de regresión logística tiene una capacidad predictiva del $78.4 \%$ y resulta ser estadísticamente significativo el coeficiente correspondiente al estrato del porcentaje de diferencia entre los precios de venta y los precios justos. De acuerdo con el signo positivo del coeficiente de regresión $\left(\beta_{5}=1.432\right)$, el 
tener un mayor porcentaje de la diferencia entre dichos precios aumenta la probabilidad de que el productor destine las ventas al consumidor, como lo indica el valor $\operatorname{del} \exp \left(\beta_{5}\right)=4.2$, cuando el porcentaje de la diferencia entre precios es de más de $25 \%$ y hasta $50 \%$. El modelo de regresión logística obtenido que incluye todas las variables objeto de estudio se presenta a continuación:

$\operatorname{Prob}(Y-1)=\frac{1}{1+\exp \left(0.774+0.023 x_{1}-0.921 x_{2}+0.121 x_{8}-0.94 x_{4}-1.432 x_{5}\right)}$

\section{Gallinas}

En el caso de las gallinas, el modelo de regresión logística tiene una capacidad predictiva del $65.4 \%$ y resulta ser estadísticamente significativo el coeficiente correspondiente a la presencia de problemas de producción. De acuerdo con el signo positivo del coeficiente de regresión $\left(\beta_{2}=\right.$ I.II9), el presentar este tipo de problema aumenta la probabilidad de que el productor destine las ventas al consumidor, de acuerdo con el valor del $\exp \left(\beta_{2}\right)=$ 3.I. El modelo de regresión logística obtenido que incluye todas las variables objeto de estudio es:

$\operatorname{Prob}(Y=1)=\frac{1}{1+\exp \left(-1.485+1.723 x_{1}-1.119 x_{2}+0.261 x_{3}-0.433 x_{4}-0.967 x_{6}\right)}$

Pavos

En el caso de los pavos, el modelo de regresión logística tiene una capacidad predictiva del $70 \%$ y resulta ser estadísticamente significativo el coeficiente correspondiente al estrato del porcentaje de diferencia entre los precios de venta y precios justos. De acuerdo con el signo positivo del coeficiente de regresión $\left(\beta_{5}=2.42 \mathrm{I}\right)$, el tener un mayor porcentaje de la diferencia entre dichos precios aumenta la probabilidad de que el productor destine las ventas al consumidor, como se expresa en el valor del $\exp \left(\beta_{5}\right)=$ II. 3 , cuando el porcentaje de la diferencia entre precios es de más de $25 \%$ y hasta $50 \%$. El modelo de regresión logística obtenido que incluye todas las variables objeto de estudio es el siguiente:

$\operatorname{Prob}(Y=1)=\frac{1}{1+\exp \left(0.874+0.66 x_{1}-0.547 x_{2}-0.665 x_{1}-1.269 x_{4}-2.421 x_{5}\right)}$

Huevo

En el caso del huevo, ninguno de los coeficientes de regresión del modelo resultó ser estadísticamente significativo. De acuerdo con este resultado, se puede afirmar que, con relación a este producto, el destino de la venta de la producción no depende de la problemática de la unidad productiva ni del porcentaje de la diferencia entre los precios de venta y los precios justos. El modelo de regresión logística obtenido que incluye todas las variables objeto de estudio se presenta a continuación:

$$
\operatorname{Prob}(Y=1)=\frac{1}{1+\exp \left(0.014-0.651 x_{1}+0.150 x_{2}+0.053 x_{3}+0.311 x_{4}+0.587 x_{5}\right)}
$$

\section{d) Análisis cualitativo}

En México, el 97.7\% de la producción agrícola nacional se obtiene mediante agricultura a cielo abierto (Inegi, 20I7), mediante la cual se práctica la agricultura extensiva en la que se aprovechan el suelo y los recursos naturales. Este es el caso de la zona sur y oriente de Yucatán, donde la producción agrícola es realizada en pequeñas unidades productivas que, en general, poseen todas o algunas de las siguientes características: a) disponen de una 
escasa infraestructura productiva; b) tienen pocas posibilidades de acceso a un crédito; c) la asistencia técnica es limitada para algunos componentes de las unidades de producción, pues con frecuencia distintas organizaciones del Gobierno y algunas ONG ofrecen talleres aislados, abarcando solo algunos aspectos muy específicos del sistema de producción; d) carecen de la infraestructura necesaria para la comercialización, tales como centros de acopio y trasporte, por lo que el mercado de sus productos es muy incierto; e) baja fertilidad del suelo y alta presencia de plagas, y, f) las iniciativas de organización del gremio de agricultores aún son muy insipientes, razón por la que no existe capacidad de gestión grupal para desarrollar capacidades de gestión que permitan mejorar sus unidades productivas y el desarrollo de cadenas de valor.

Se identificó que, de acuerdo con la Encuesta Nacional Agropecuaria (ENA) (Inegi, 2017), a nivel nacional, el 51.5\% de la producción agrícola fue vendida a los intermediarios y el $25 \%$ se vendió al consumidor, el resto, a otros mercados. En el caso de la zona en donde se llevó a cabo el presente estudio, sucedió algo similar: el 42.9\% de la producción fue vendida a los intermediarios y el $30.6 \%$ al consumidor.

En este sentido y de acuerdo al análisis realizado con productores y personal técnico involucrado en la comercialización de los productos, se observa que la venta a los intermediarios, por un lado, representa una ventaja, puesto que estos compran la totalidad de la producción y pagan en efectivo, pero, por el otro lado, significa una gran desventaja en cuanto a que, generalmente, pagan a muy bajos precios, condición que resulta complicada para los pequeños productores, ya que su utilidad es escasa y en ocasiones terminan perdiendo después de haber trabajado tanto. A continuación, se presentan algunos testimonios: los dos primeros corresponden a técnicos que participan con los productores en sistemas de comercialización y los siguientes dos a productores:

\footnotetext{
El productor se desanima a cosechar por el precio que se le pone a su producción, que ni siquiera vale la pena ponerse a cosechar, como por ejemplo un huacal de limón le pagan 30 pesos. Prefieren dejar que se caiga por no tener los recursos para salir en busca de otros mercados.

Cuando los productores van a vender a un mismo mercado o lugar, ellos [los intermediarios] se ponen de acuerdo con los precios y además buscan pretextos sobre los tamaños o calidad de los productos, para reventar el precio y, si no les vende en un lapso de tiempo, en cuestión de horas, le dicen que ya consiguieron el producto o que ya se van a retirar, con el fin de rematarles sus productos y pagarle al más bajo precio. Tienen coyotes a su disposición para comprar barato y revender.

Los intermediarios trabajan a su favor, es decir, siempre ven ganar más y pagar menos a nosotros como productores, debido que en algunas ocasiones no tenemos con qué sacar la cosecha, por eso se aprovechan.

Los intermediarios vienen y nos compran en huacales de $30 \mathrm{~kg}$, cuando luego ellos lo venden en huacales de i8kg, con un precio superior al de compra, abusan porque nosotros no tenemos posibilidades de vender en otros mercados.
}

Existen distintos factores que no permiten que los productores puedan negociar y que estén sujetos a los precios que fijen los intermediarios, entre los que se pueden citar los siguientes: la falta de información actualizada sobre los precios de sus productos, las malas condiciones de los caminos para movilizar sus cosechas, la falta de transporte, el compromiso por préstamos que los intermediarios proporcionan a los productores durante el proceso de producción, entre otros.

\section{Discusión}

La definición de comercio justo, acordada en el 2009 por la World Fair Trade Organization y la Organización Internacional para el Etiquetado del Comercio Justo (WFTO-FLO, 2009), descrita en la Carta de los Principios de Comercio Justo, establece que

el comercio justo es una relación de intercambio comercial, basada en el diálogo, la transparencia y el respeto, que busca una mayor equidad en el comercio internacional. Contribuye al desarrollo sostenible, ofreciendo mejores condiciones comerciales y asegurando los derechos de los pequeños productores y trabajadores marginados. (p. 6) 
El comercio justo es considerado como una de las modalidades impulsadas por la llamada economía social, cuyos principios se basan en la cooperación, la solidaridad, la igualdad, la autogestión, el respeto por los derechos del hombre, el cuidado del medio ambiente y el fomento de la economía local, en busca de un comercio ético y responsable (Masson, 20I2; García, 20II; Kestmont y Fraselle, 2006).

El concepto de precio justo encuentra sus orígenes en el pensamiento griego de Aristóteles, ya que él fue el primero en referirse a los asuntos de la justicia, en relación con el establecimiento de los precios, a través de la percepción del valor de cambio equitativo en el intercambio comercial de su época, de ahí surge la noción ética del justo precio (Valdebenito, 2016). El autor citado asegura que, en la actualidad, las enseñanzas aristotélicas fueron suplantadas por la lógica de la actividad racional, liderada por la guía del bomoeconomicus, "ya que se sustituye la noción de un precio justo regido por la estimación común y el acto moral por la noción de un precio nominativo regido únicamente por la estimación individual y las dinámicas del mercado” (Valdebenito, 20I6, p. 78).

Las prácticas de precio justo, precisamente, intentan regresar a los orígenes de la justicia ética con el establecimiento del precio, al considerar que este es posible, viable y acorde con la valoración de los compradores, pero que también sea suficiente para cubrir los costos, gastos y reinversión de un método de producción sostenible, sin denigrar el trabajo de los productores y obteniendo márgenes de ganancias suficientes para mejorar la vida de las familias productoras y de sus comunidades.

El comercio justo es ampliamente referido dentro de un contexto de comercialización internacional (López et ál., 20I9; Coscione y Mulder, 20I7; Calisto, 20I6), aunque también es considerado como una herramienta para el desarrollo local (García, 20II), ya que es desde la comunidad donde se origina la actividad productiva y en donde se conforman las redes productivas y comerciales a nivel local y regional, así mismo, en donde se espera que las ganancias y las primas sociales, ${ }^{\mathrm{i}}$ en su caso, se aprovechen para el bien de las familias productoras y para la comunidad en general.

Para efectos de este trabajo, se consideró este último enfoque de las prácticas de comercio justo desde lo local, debido a que los productores, los sujetos de estudio, no tienen una certificación de comercio justo de alguna institución internacional que los avale; por lo tanto, estos productores no han comercializado sus productos en el ámbito internacional. Sin embargo, la Agencia de Desarrollo Humano Local (ADHL), que incide en la producción, distribución y comercialización de los productos de los sujetos de estudio, ubicados en los ocho municipios que abarca el proyecto mencionado (financiado por la Fundación Kellogs), sigue los propósitos relacionados con las prácticas de comercio justo y el precio justo.

La ADHL forma parte del modelo alternativo que intenta corregir las fallas del sistema capitalista actual, pues las organizaciones y cooperativas que pertenecen a la ADHL tienen una relación comercial basada en el diálogo, la transparencia, la democracia, el respeto y la búsqueda de la gestión ambiental sostenible. Los productores reciben el apoyo de estas asociaciones o instituciones, las cuales les ofrecen créditos con bajos intereses y mínimos requisitos, canales de distribución por medio de sus centros de acopio, asesoría técnica, legal o comercial, entre otros beneficios.

A través de la intervención de la ADHL, se intenta disminuir la pobreza, la desigualdad, la exclusión social, la migración campo-ciudad (principalmente, de los jóvenes) y las ventas a intermediarios que reducen el precio y dejan bajos márgenes de ganancia para los productores. Asimismo, la ADHL, a nivel organización, fomenta el respeto a los derechos humanos, la gestión ambiental sostenible, el trabajo cooperativo y la formación del capital social, para así mejorar el sistema productivo local y lograr una mayor equidad. A nivel individual, también fomenta la autoestima, el reconocimiento social, la autoconfianza de los productores, el orgullo cultural, el empoderamiento de los productores, la tranquilidad de tener mejor control sobre su futuro y el sentido de pertenencia.

En los países latinoamericanos, los problemas principales relacionados con la producción o comercialización de los productos agropecuarios, en un entorno de unidades económicas rurales de subsistencia, son: 
a) Relacionados a la tierra:

- Recursos naturales degradados, principalmente, debido a prácticas de producción no sustentables, la deforestación y la sobreexplotación de recursos (Secretaría de Agricultura y Desarrollo Rural del Gobierno Federal (Sagarpa) y Organización de las Naciones Unidas para la Alimentación y la Agricultura (FAO), 20I2). En Yucatán, en el 2006, el 20\% de las unidades productivas consideraron como uno de sus principales problemas la pérdida de fertilidad del suelo (Inegi, 2007).

- Eventos climatológicos adversos (Sagarpa y FAO, 20I2; Benítez-García et ál., 2015). En Yucatán, en el 2006, el $80 \%$ de las unidades productivas consideraron que sus pérdidas fueron ocasionadas por cuestiones climáticas (Inegi, 2007).

b) Relacionados a la producción:

- Baja dotación de bienes de capital. El bajo nivel de ingresos de las unidades económicas rurales de subsistencia genera un círculo negativo de pobreza, ya que las familias que trabajan en estas unidades no pueden invertir en activos productivos (Sagarpa y FAO, 2012).

- Bajo nivel tecnológico, debido a la nula capacidad de inversión productiva y de innovación, la inadecuada aplicación de las tecnologías o el insuficiente (Sagarpa y FAO, 20I2).

- La falta de infraestructura, recursos e información aumenta los costos de transacción de los agricultores y limita sus oportunidades (Fanjul y Guereña, 2010). En Yucatán, en el 2006, el I6\% de las unidades productivas mencionaron que uno de sus principales problemas es la insuficiente infraestructura que tienen para la producción (Inegi, 2007).

- Falta de crédito. En Yucatán, en el 2006, el 28\% de las unidades productivas mencionaron que uno de sus principales problemas es el difícil acceso al crédito (Inegi, 2007).

c) Relacionados a la comercialización:

- Bajo nivel de negociación para la comercialización. En el campo existe una multitud de pequeños campesinos desorganizados que no tienen fuerza de negociación, a la vez que tienen pocos recursos para incrementar la productividad y poder competir en el mercado, bajo unas mejores condiciones (FAO, 200I).

- No tienen un sistema que les permita hacer frente a la incertidumbre y la volatilidad de los mercados agrícolas nacionales (Fanjul y Guereña, 20ıо).

d) Relacionados al trasporte:

- Falta de disponibilidad. El transporte es un elemento fundamental para la comercialización de productos agropecuarios, ya que, cuando hay poca disponibilidad de productos, la dificultad y los costos se incrementan, lo que implica muchas veces que los productores no puedan sacar los productos de su zona o que no los puedan vender, y es en ese momento cuando el campesinado recurre más a la intermediación (López-Posada y Pachón-Ariza, 2017).

e) Relacionados a las prácticas de comercio a intermediarios y precios justos:

- Precios de venta realizados por debajo del deseado o el justo (según la valoración del productor). El precio de venta que el productor pacta con el intermediario representa, en muchos casos, aproximadamente un tercio del precio al que los productos pueden ser vendidos, de acuerdo al margen de utilidad esperado; generalmente, estos precios no cubren el costo de producción (Balanzátegui et ál., 2016). Asimismo, con respecto a la forma en la que se le asigna el precio del producto, generalmente, las unidades productivas en zonas rurales no llevan un registro o una contabilidad para determinar los costos de producción y gastos generales y, por lo tanto, para 
determinar el precio del producto; muchas veces, los productores solo toman en cuenta algunos gastos, sin considerar su mano de obra, o lo comparan con su competencia (Bojórquez et ál., 2019).

- Exceso de intermediarios. Una de las consecuencias de la existencia de los intermediarios en los mercados mayoristas es que generan que los productos lleguen a quintuplicar su precio desde el productor hasta el consumidor final ((Balanzátegui et ál., 2016). Desafortunadamente, en las zonas que se localizan lejos de las zonas urbanas, los productores tienen menos probabilidades de comercializar sus productos a precios justos, debido a que tienen varias limitaciones como la logística, dónde y cuándo vender los productos, el abandono de sus actividades, entre otros. Por esta razón, optan por vender a intermediarios y algunos de ellos les ofrecen menos del precio deseado o justo, aprovechando que el productor desconoce los precios de sus productos en los mercados urbanos, por lo que el intermediario se lleva la mayor parte de las ganancias (Bojórquez et ál., 2019).

- Creciente estrechamiento de los canales de procesamiento y distribución, en manos de unos pocos, exclúyelo que hace que se excluya a los pequeños productores (Fanjul y Guereña, 20го).

En México, estos problemas tienen como consecuencias el abandono del campo, la migración campo-ciudad, el aumento de los niveles de violencia y de marginación en zonas rurales, el trabajo informal, entre otros. Los problemas antes descritos de los pequeños productores enmarcan y justifican el análisis de las variables de este estudio. En la tabla 7 se presenta un resumen de los resultados de la verificación de las hipótesis del presente estudio.

TABLA 7.

RESULTADOS DE LA VERIFICACIÓN DE LAS HIPÓTESIS DE INVESTIGACIÓN PARA LOS PRODUCTOS SELECCIONADOS

\begin{tabular}{|c|c|c|c|}
\hline & $\mathrm{Hl}^{*}$ & $\mathrm{H} 2$ ** & $\mathrm{H}^{* \star \star *}$ \\
\hline \multicolumn{4}{|c|}{ Productos agricolas } \\
\hline Calabaza & $\begin{array}{l}\text { No se } \\
\text { confirma }\end{array}$ & $\begin{array}{l}\text { No hay relación } \\
\text { significativa }\end{array}$ & $\begin{array}{l}\text { Se confirma en el caso de que la } \\
\text { unidad productiva presente } \\
\text { problemas relacionados con la } \\
\text { tierra }\end{array}$ \\
\hline Frijol & $\begin{array}{l}\text { No se } \\
\text { confirma }\end{array}$ & $\begin{array}{l}\text { No hay relación } \\
\text { significativa }\end{array}$ & $\begin{array}{l}\text { No se confirma. Para este } \\
\text { producto, el tener problemas con } \\
\text { el transporte aumenta la } \\
\text { probabilidad de que el productor } \\
\text { destine las ventas al consumidor }\end{array}$ \\
\hline Maiz & $\begin{array}{l}\text { No se } \\
\text { confirma }\end{array}$ & $\begin{array}{l}\text { No hay relación } \\
\text { significativa }\end{array}$ & No se confirma \\
\hline
\end{tabular}

\footnotetext{
${ }^{*} \mathrm{H}_{\mathrm{I}}$ se presentan diferencias significativas entre los porcentajes de la diferencia entre los precios de venta y los precios justos (según valoración del productor) por destino de la venta.

${ }^{* *} \mathrm{H}_{2}$ : a mayor porcentaje de la diferencia entre el precio de venta y el precio justo (según valoración del productor), mayor es la probabilidad de que el destino de la venta sea el intermediario. ${ }^{* * *} \mathrm{H}_{3}$ : existe una mayor probabilidad de que la producción se destine al intermediario, en el caso de que la unidad productiva presente problemas de relacionados con la tierra, la producción, el transporte o la comercialización. Fuente: elaboración propia con base en los resultados del estudio.
} 
TABLA 7.

RESULTADOS DE LA VERIFICACIÓN DE LAS HIPÓTESIS DE INVESTIGACIÓN PARA LOS PRODUCTOS SELECCIONADOS

\begin{tabular}{|c|c|c|c|}
\hline \multicolumn{2}{|c|}{$\begin{array}{l}\text { Productos } \\
\text { pecuarios }\end{array}$} & \multirow[b]{2}{*}{$\begin{array}{l}\text { No se confirma. Para este } \\
\text { producto, a mayor } \\
\text { porcentaje de la diferencia } \\
\text { entre el precio de venta y el } \\
\text { precio justo, la probabilidad } \\
\text { de que el destino de la venta } \\
\text { sea al consumidor es mayor }\end{array}$} & \multirow[b]{2}{*}{ No se confirma } \\
\hline Miel & $\begin{array}{l}\text { Se } \\
\text { confirma }\end{array}$ & & \\
\hline Huevo & $\begin{array}{l}\text { No se } \\
\text { confirma }\end{array}$ & No se confirma & No se confirma \\
\hline Gallinas & $\begin{array}{l}\text { No se } \\
\text { confirma }\end{array}$ & No se confirma & $\begin{array}{l}\text { No se confirma. Para este } \\
\text { producto, el tener problemas de } \\
\text { producción aumenta la } \\
\text { probabilidad de que el productor } \\
\text { destine las ventas al consumidor }\end{array}$ \\
\hline Pavos & $\begin{array}{l}\text { No se } \\
\text { confirma }\end{array}$ & $\begin{array}{l}\text { No se confirma. Para este } \\
\text { producto, a mayor } \\
\text { porcentaje de la diferencia } \\
\text { entre el precio de venta y el } \\
\text { precio justo, la probabilidad } \\
\text { de que el destino de la venta } \\
\text { sea al consumidor es mayor }\end{array}$ & No se confirma \\
\hline
\end{tabular}

\footnotetext{
${ }^{*} \mathrm{H}_{\mathrm{I}}$ : se presentan diferencias significativas entre los porcentajes de la diferencia entre los precios de venta y los precios justos (según valoración del productor) por destino de la venta.

${ }^{* *} \mathrm{H}_{2}$ : a mayor porcentaje de la diferencia entre el precio de venta y el precio justo (según valoración del productor), mayor es la probabilidad de que el destino de la venta sea el intermediario. ${ }^{* * *} \mathrm{H}_{3}$ : existe una mayor probabilidad de que la producción se destine al intermediario, en el caso de que la unidad productiva presente problemas de relacionados con la tierra, la producción, el transporte o la comercialización. Fuente: elaboración propia con base en los resultados del estudio.
}

En la región que nos ocupa y para los productos analizados, se ha confirmado, en el caso específico de la miel, que cuando la diferencia porcentual promedio de los precios de venta y los precios justos es significativa, es más probable, con relación al destino de la venta, que los productos se destinen al consumidor (9.5\%) que al intermediario (6.7\%). Es decir, el precio de la miel está más controlado en términos de prácticas de comercio justo, en el caso de la venta al intermediario, debido a que la producción y comercialización de este productos representa una de las más importantes del estado de Yucatán y en México. De hecho, en las las exportaciones de este producto, México ocupa la tercera posición en América Latina y la sexta en el mundo (Magaña et ál., 20I6). Por su parte, la participación del intermediario en el precio final de este producto es bajo (16\%), a comparación de la participación 
del productor, que es en promedio del 63\% (González et ál., 20I4). En los últimos años, se han formado cooperativas con un enfoque de economía solidaria y comercio justo, en torno a este producto.

Cabe anotar que el análisis multivariado de regresión logística ha permitido identificar la influencia que tiene el tipo de problema de la unidad productiva sobre el destino de la venta de lo producido. Específicamente, con relación a los productos analizados, se observa un incremento en la probabilidad de que la producción se destine al intermediario, en el caso de que en la unidad productiva se presenten problemas de la tierra (como en el caso de la calabaza), y de que la producción se destine al consumidor, en el caso de que la unidad productiva tenga problemas con el transporte (como en el caso del frijol) y del proceso productivo (en el caso de las gallinas).

Como señala Acosta Leal (2014), existen tres elementos claves para definir los precios: la demanda, la competencia en el mercado y los costos de producción. Resulta relativamente fácil conocer los dos primeros, sin embargo, es difícil conocer cuáles serán los costos reales de producción, puesto que, en general, los pequeños productores no llevan el registro de los costos; sin esta información, resulta complicado establecer un precio que indique si es o no justo lo que se paga al productor. En este sentido, se requiere que las instancias encargadas de trabajar con los pequeños productores desarrollen estrategias que permitan hacer las estimaciones de los costos de producción de los diversos productos agropecuarios.

Asimismo, para que los productores reciban un mejor precio, se requiere buscar otros mercados sensibles al comercio justo. Aunque algunos empresarios de la rama de los restaurantes expresan que quieren contribuir a los productores, se desencadena una competencia difícil por precios y los primeros tienden a preferir los precios más bajos. A pesar de esta situación, existe un mercado consciente y dispuesto a pagar mejores precios a los productores y productoras. En Tulum, Q. Roo, se tuvo la experiencia con la comercialización del huevo de gallina libre de jaula, proveniente de mujeres del sur de Yucatán: algunos competidores tenían acaparado el mercado de huevo con apariencia y características organolépticas similares y, aunque el precio era considerablemente menor, muchos clientes estuvieron dispuestos a comprar a un precio más justo, al sentirse motivados de apoyar a las mujeres productoras y al confiar más en sus prácticas agropecuarias. En este sentido, se encontró que, al resaltar la propuesta de valor del producto por sobre el precio, se abren oportunidades para mejores condiciones comerciales.

En general, se pudo constatar que la percepción que tienen los productores con respecto a los precios que reciben por la venta de sus productos son bajos o muy bajos, por lo tanto, se puede dictaminar que los precios que los productores reciben por la venta de sus productos no son los justos, ya que en promedio respondieron que los intermediarios les pagan $53 \%$ (para los productos agrícolas) y $31 \%$ (para los productos pecuarios) menos del precio que ellos hubieran deseado, lo que, para efectos de esta investigación, se asimila como el precio justo desde la percepción del productor.

\section{Conclusiones}

La implementación de las prácticas de comercio y precio justos en el sector agropecuario mexicano enfrenta grandes y diversos retos; el diagnóstico de la situación prevaleciente permite identificar áreas de oportunidad y posibilidades para ello. En este sentido, la realización de estudios en pequeñas regiones permite focalizar la situación y problemática prevalecientes, para así establecer mejores estrategias y acciones que fomenten el desarrollo del comercio y precio justos como una alternativa para beneficiar a los actores involucrados en el proceso de la producción, principalmente.

Los resultados obtenidos en el presente estudio contradicen la idea de que los pequeños productores agrícolas se dirigen directamente a los intermediarios para venderles sus productos, en caso de que presenten algún tipo de problema con respecto a la tierra, la producción, la comercialización, el transporte o, incluso, la falta de 
precios justos. Lo anterior solo se cumple en el caso de la calabaza, en el que sí se confirmó esta tercera hipótesis, específicamente, en caso de presentarse problemas con la tierra. La razón de ser de estos resultados puede ser, precisamente, el reducido tamaño de producción que tienen estos trabajadores, debido a que, como se mencionó en la metodología, la mayoría de las unidades de producción eran de subsistencia y, por lo tanto, la mayor parte de los alimentos se producen para el consumo interno familiar o de la comunidad.

Se afirma que, de forma general, en el contexto de una producción de subsistencia, en particular con los productos agropecuarios analizados y en los municipios estudiados, los problemas de la tierra, producción, comercialización, transporte o falta de precios justos (según la percepción del productor), no son causas por las que el productor venda sus productos a los intermediarios, en la mayoría de los casos. Se pudo observar que incluso en algunos productos, cuando el productor tiene alguno o algunos de estos problemas, tiende a vender sus productos al consumidor. Se entiende que, en el entorno en que se desenvuelven, el consumidor final será en su mayoría local, cercano al productor y con características sociodemográficas parecidas.

Ante este panorama, se identificó que se requiere emprender acciones enfocadas al fortalecimiento de las capacidades de los pequeños productores, en aspectos como la gestión, organización, administración y comercialización. Para ello, es necesario que las instituciones del Gobierno, las organizaciones no gubernamentales (ONG), el sector empresarial y la academia desarrollen programas enfocados a la mejora de un sistema integral de producción agropecuaria, centrado en fortalecer las cadenas de valor.

En ese contexto, otros factores como el desconocimiento de los mercados y de las cadenas de valor, los rezagos en la tecnología \#concebida como elemento propulsor de la productividad y calidad de los productos\#, la prevaleciente falta de vinculación de instituciones y programas, el intermediarismo, la reiterada dificultad del acceso a créditos, la falta de infraestructura, recursos e información básica, entre otros, se suman al difícil panorama que atraviesa la actividad agropecuaria rural en Yucatán. En este sentido, aún hace falta mucho por hacer para lograr un desarrollo agropecuario integral, además de que parte de las condiciones adversas tienen que ver en gran medida con la idiosincrasia, con los bajos niveles educativos en el campo y con la falta de visión empresarial, los cuales, se sabe, son factores limitantes en un horizonte a corto plazo.

Aún es posible profundizar en el conocimiento sobre los diversos factores que influyen en el resultado final del sistema utilizado por los pequeños productores que, dependiendo de los niveles de eficiencia y eficacia de sus unidades productivas, se traduce en la generación de un bien escaso o abundante, situación que conlleva a que las familias productoras empeoren, se mantengan o mejoren sus condiciones de vida. Sin embargo, la reflexión presente se concentra en la relevancia que tiene la comercialización en el resultado final, ya que, dependiendo de los canales a los que se tenga acceso, los ingresos de los productores pueden ser más sustantivos.

Finalmente, cabe destacar que los productores están muy arraigados a su actividad y en su mayoría son conscientes que requieren de organización para lograr mejores resultados, además, que deben realizar acciones como: gestionar subsidios para infraestructura productiva, disponer de asistencia técnica permanente, tener acceso a un sistema de ahorro y crédito, realizar siembras escalonadas de sus productos para evitar que todos tengan la producción al mismo tiempo, diversificar sus productos, contar con un sistema de información que les permita conocer el precio actual de sus productos y contar con infraestructura para la comercialización en diversos canales, entre otros aspectos.

Es imperativo para el desarrollo local que los pequeños productores de zonas marginadas tengan mejores condiciones y oportunidades para la producción y comercialización de sus productos, en las que prevalezcan las prácticas del comercio y precios justos. 


\section{Referencias}

Acosta Leal, D. A. (2014). Fijación de precios en mercados campesinos de Bogotá. Caso hortalizas frescas de Fómeque y Chipaque (Cundinamarca). https://repositorio.unal.edu.co/handle/unal/52259

Alderete, A. (2006). Fundamentos del Análisis de Regresión Logística en Investigación Psicológica, Revista Evaluar, 6(I), 52-67. http://dx.doi.org/10.35670/1667-4545.v6.nI.534

Balanzátegui, J., Sánchez, P. y Balanzátegui, R. (2016). El precio justo en los productos agrícolas en el Ecuador. Revista Observatorio de la Economía Latinoamericana, I-20. http://www.eumed.net/cursecon/ecolat/ec/2016/pr ecio-justo.html

Benítez-García, E., Jaramillo-Villanueva, J., Escobedo-Garrido, S. y Mora-Flores, S. (2015). Caracterización de la producción y del comercio de café en el municipio de Cuetzalan, Puebla. Agrícultura, sociedad y desarrollo, I2(2). http://www.scielo.org.mx/scielo.php?script=sci_arttext\&pid=SI870-54722015000200004

Bojórquez, A., Suárez-Nuñez, T. y Flores, A. (2019). Microempresas femeninas y las TIC. Fontamara.

Calisto, M. (2016). Comercio justo, seguridad alimentaria y globalización: construyendo sistemas alimentarios alternativos. Iconos, Revista de Ciencias Sociales, 55, 215-240. http://dx.doi.org/10.17141/iconos.55.2016.1959

Coscione, M. y Mulder, N. (Eds.) (2017). El aporte del comercio justo al desarrollo sostenible. Repositorio Digital Comisión Económica para América Latina y el Caribe. Cepal, CLAC y Fairtrade. https://repositorio.cepal.org/ handle/II $362 / 42404$

Díaz del Castillo, J. F. C. (2013). La intermediación como un impedimento al desarrollo del pequeño productor de Medellín. Revista Corpoica Ciencia y Tecnología Agropecuaria, I4(I), 27-32. http://www.scielo.org.co/pdf/cct a/vi4ni/vi4nia04.pdf

Fanjul, G., \& Guereña, A. (2010). Acceso a los mercados agrícolas Oportunidades para superar la pobreza rural. OXFAM Intermón. https://www.oxfamintermon.org/sites/default/files/documentos/files/I0I209_IO_Ac ceso_a_Mercados.pdf

García, A. (20II). El comercio justo: ¿una alternativa de desarrollo local? Polis, 7(I), I05-I40. http://www.scielo.org .mx/scielo.php?script=sci_arttext\&pid=SI870-23332011000100005

García, C. M. (2016). Pobreza y globalización ¿existe correlación condicional? Una aproximación desde América latina. Journal Globalization, Competitiveness and Governability, Io(2),7I-86. https://doi.org/10.3232/GCG.2016.V I0. $\mathrm{N}_{2} .04$

González, F., Rebollar, S., Hernández, J. y Guzmán, E. (20I4). La comercialización de la miel en el sur del estado de México.Revista Méxicana de Agonegocios, 34, 806-815. http://www.redalyc.org/articulo.oa?id=I4131514015

Goyas, R. (2019). Transformaciones y dinámicas espaciales en un ejido del centro de Jalisco. Región y sociedad, 3I, I-22. http://dx.doi.org/10.22198/rys2019/31/1007

Hosmer, D. W., \& Lemeshow, S. (2000). Applied Logistic Regression. 2da edición. John Wiley \& Sons, Inc.

Instituto Nacional de Estadística y Geografía [Inegi]. (2007). Censos Agropecuarios. Inegi. https://www.inegi.org.m x/programas/cagf/2007/\#Tabulados

Instituto Nacional de Estadística y Geografía [Inegi]. (20I0). Censo de Población y Vivienda 20Io. Inegi. https://ww w.inegi.org.mx/programas/ccpv/2010/\#Tabulados

Instituto Nacional de Estadística y Geografía [Inegi]. (2015). Encuesta Intercensal 2015. Inegi. https://www.inegi.or g.mx/programas/intercensal/2015/\#Tabulados

Instituto Nacional de Estadística y Geografía [Inegi]. (2017). Encuesta Nacional Agropecuaria (ENA 2017). Conociendo el campo de México. Inegi. https://www.inegi.org.mx/programas/ena/2017/_Tabulados 
Kestmont, M. P., \& Fraselle, N. (2006). Comercio justo y comercio ético: nuevas formas de relaciones comerciales. Puente@Europa, 4(2), I8-20. https://puenteeuropa.unibo.it/article/view/5095/4853

López-Posada, J. y Pachón-Ariza, F. (2017). Identificación de ventajas y desventajas de los canales de comercialización en las economías campesinas de dos municipios de Meta y Cundinamarca, Colombia. Revista Investigación Desarrollo e Innovación, 8(I), 35-47. https://doi.org/10.19053/20278306.v8.nI.2017.7369

López, C., Zamora, C., Cortina, S. y Pat, L. (2019). Campesinos a contracorriente. Estrategias organizativas, productivas y comerciales de la cooperativa indígena campesina Maya Vinic. Región y sociedad, 3I, I-20. https ://regionysociedad.colson.edu.mx:8086/index.php/rys/article/view/ı079

Magaña, M., Tavera, M., Salazar, L. y Sanginés, J. (2016). Productividad de la apicultura en México y su impacto sobre la rentabilidad. Revista Mexicana de Ciencias Agrícolas, 75), I103-III5. http://www.scielo.org.mx/scielo. php?script=sci_arttext\&pid=S2007-09342016000501103

Masson, F. (20I2). Aproximaciones al análisis de la noción de valor en el establecimiento del "precio justo." VII Jornadas de Sociología de la UNLP. La Plata, Argentina, Universidad Nacional La Plata (UNLP). http://jo rnadassociologia.fahce.unlp.edu.ar

Medina S. (2013). Comercio justo: una perspectiva general; Revista Comercio Exterior (Bancomext), 63(I), 2-7. http:// revistas.bancomext.gob.mx/rce/magazines/r52/I/COMERCIO_JUSTO.pdf

Medina, M. B., \& Flores, A. (2012). Análisis de las empresas exportadoras de miel en Yucatán. Las nuevas alternativas de comercialización: Comercio Justo y Apicultura Orgánica. Editorial Académica Espan\#ola.

Secretaría de Agricultura y Desarrollo Rural del Gobierno Federal [Sagarpa] y Organización de las Naciones Unidas para la Alimentación y la Agricultura [FAO]. (2012). Diagnóstico del sector rural y pesquero de México 2012. Sagarpa y FAO. http://www.sagarpa.mx/programas2/evaluacionesExternas/Lists/Otros\%20Estudios /Attachments/47/1\%20Diagn\%C3\%B3stico\%20del\%20sector\%20rural\%20y\%2opesquero.pdf

Organización de las Naciones Unidas para la Agricultura y la alimentación [FAO]. (200I). La agricultura contractual. Departamento de Agricultura y Protección del Consumidor. Organización de las Naciones Unidas. ht tp://www.fao.org/ag/esp/revista/pdf/ago9.pdf

Valdebenito, M. (2016). La doctrina del Justo Precio, desde Aristóteles hasta la escuela moderna subjetiva del valor. Economía y Sociedad, XX(34), 60-79. http://www.redalyc.org/articulo.oa?id=51046653004

World Fair Trade Organization [WFTO] y la Organización Internacional para el Etiquetado del Comercio Justo [FLO]. (2009). Carta de los Principios del Comercio Justo. World Fair Trade Organization, Fairtrade. https://wft o.com/sites/default/files/Charter-of-Fair-Trade-Principles-Final (SP).PDF

World Fair Trade Organization [WFTO]. (2019). Los io Principios de Comercio Justo. Home of Fair Trade Enterprises. https://wfto.com/who-we-are-Io-principles-of-fair-trade

\section{Notas}

* Artículo de investigación producto del proyecto "Fortalecimiento del capital social para contribuir a la seguridad y soberanía alimentaria en ocho municipios del estado de Yucatán”, el cual fue financiado por la Fundación Kellogg con el número P3034405, en el periodo del I de abril de 2016 al 30 de mayo de 2019 . El objetivo general del proyecto es: "Fortalecer el capital social de las comunidades a través de la coordinación intersectorial y la participación ciudadana, con el fin de contribuir a la seguridad y la soberanía alimentaria de las familias participantes". Este artículo contribuye específicamente al objetivo 2: "Establecer una red de cooperación para la producción y la comercialización a través de la implementación de un mercado solidario”, por lo que, el establecimiento y la percepción del precio justo apoya a las prácticas de comercio justo y evita que los intermediarios se aprovechen de los productores "rematando" sus productos a muy bajos precios. 
i La prima social es lo que pagan los consumidores a los grupos o cooperativas que tienen productos con certificación de comercio justo. Esta prima ayuda a los productores a mejorar la infraestructura de sus comunidades, tales como hospitales, escuelas, transporte, agua corriente, entre otros. La decisión de la utilización de esta prima social debe ser a través de mecanismos democráticos.

\section{BY}

